\title{
Impacts of meteorology and emission variations on the heavy air pollution episode in North China around the 2020 Spring Festival
}

\author{
Wenbo XUE ${ }^{1,2}$, Xurong $\mathrm{SHI}^{1}$, Gang $\mathrm{YAN}^{1}$, Jinnan WANG ${ }^{1}$, Yanling XU ${ }^{1}$, Qian TANG ${ }^{1}$, \\ Yanli WANG ${ }^{1}$, Yixuan $Z H E N G^{1} \&$ Yu LEI ${ }^{1 *}$ \\ ${ }^{1}$ Center of Air Modeling and Systems Analysis, Chinese Academy for Environmental Planning, Beijing 100012, China; \\ ${ }^{2}$ State Environmental Protection Key Laboratory of Environmental Planning and Policy Simulation, Chinese Academy for Environmental \\ Planning, Beijing 100012, China
}

Received March 21, 2020; revised September 14, 2020; accepted September 25, 2020; published online January 12, 2021

\begin{abstract}
Based on the Weather Research and Forecasting model and the Models-3 community multi-scale air quality model (WRF-CMAQ), this study analyzes the impacts of meteorological conditions and changes in air pollutant emissions on the heavy air pollution episode occurred over North China around the 2020 Spring Festival (January to Februray 2020). Regional reductions in air pollutant emissions required to eliminate the $\mathrm{PM}_{2.5}$ heavy pollution episode are also quantified. Our results found that meteorological conditions for the Beijing-Tianjin-Hebei and surrounding " $2+26$ " cities are the worst during the heavy pollution episode around the 2020 Spring Festival as compared with two other typical heavy pollution episodes that occurred after 2015. However, because of the substantial reductions in air pollutant emissions in the " $2+26$ " cities in recent years, and the $32 \%$ extra reduction in emissions during January to February 2020 compared with the baseline emission levels of the autumn and winter of 2019 to 2020, the maximum $\mathrm{PM}_{2.5}$ level during this heavy pollution episode around the 2020 Spring Festival was much lower than that in the other two typical episodes. Yet, these emission reductions are still not enough to eliminate regional heavy pollution episodes. Compared with the actual emission levels during January to February 2020, a 20\% extra reduction in air pollutant emissions in the " $2+26$ " cities (or a $45 \%$ extra reduction compared with baseline emission levels of the autumn and winter of 2019 to 2020) could help to generally eliminate regionwide severe pollution episodes, and avoid heavy pollution episodes that last three or more consecutive days in Beijing; a $40 \%$ extra reduction in emissions (or a $60 \%$ extra reduction compared with baseline emission levels of the autumn and winter of 2019 to 2020) could help to generally eliminate regionwide and continuous heavy pollution episodes. Our analysis finds that during the clean period after the heavy pollution episode around the 2020 Spring Festival, the regionwide heavy pollution episode would only occur with at least a 10-fold increase in air pollutant emissions.
\end{abstract}

Keywords " $2+26 ”$ cities, 2020 Spring Festival, Heavy air pollution episode, WRF-CMAQ model

Citation: Xue W, Shi X, Yan G, Wang J, Xu Y, Tang Q, Wang Y, Zheng Y, Lei Y. 2021. Impacts of meteorology and emission variations on the heavy air pollution episode in North China around the 2020 Spring Festival. Science China Earth Sciences, 64(2): 329-339, https://doi.org/10.1007/s11430-0209683-8

\section{Introduction}

Around the 2020 Spring Festival in China from January to February 2020, emissions of air pollutants over North China

* Corresponding author (email: leiyu@caep.org.cn) has reduced substantially due to the reductions in socioeconomic activity levels. However, during this period, two severe air pollution episodes occurred. The contradiction between "relatively low activity levels" and "relatively high pollution levels" has attracted wide attention. Air quality is mainly determined by atmospheric environmental capacity 
and emissions of air pollutants (Cheng and Li, 2010; Chang et al., 2019; Liu et al., 2016; Wang et al., 2014, 2015; Zhang et al., 2012, 2015). From the perspective of environmental management, atmospheric environmental capacity is mainly affected by natural and anthropogenic factors. Natural factors include meteorological conditions, topography, and landforms, etc. Human factors include the regional distribution of pollutant emissions, the composition of air pollutants, and the physical and chemical interaction between different pollutants (Xue et al., 2017; Xu et al., 2018; Wang et al., 2012). From the perspective of chemical mechanisms, Huang et al. (2020a) showed that emission reductions especially NOx during the 2020 Spring Festival have generally increased the atmospheric oxidation capacity over eastern China. The increased atmospheric oxidation contributed to the formation of secondary aerosols. In BeijingTianjin-Hebei and its surrounding areas, which is a relatively small spatial scale, meteorological conditions have an important impact on the atmospheric environmental capacity because the topography and landforms and the spatial distribution of air pollutant emissions would not change substantially in the short term. Therefore, this study analyzes the heavy air pollution episodes from the perspectives of meteorological conditions and air pollutant emissions.

Several questions have been the focus of the scientific community and the public: what are the meteorological conditions during the heavy pollution episode around the 2020 Spring Festival compared with other typical heavy pollution episodes; how much pollutant emissions still need to be reduced to substantially improve air quality; what is the difference in atmospheric environmental capacity between the pollution episodes and the following clean period around the 2020 Spring Festival. Constrained by a specific air quality target, this study uses the comprehensive emission reduction requirements of major air pollutants to characterize the atmospheric environmental capacity. We explore the cause of the two heavy pollution episodes over the BeijingTianjin-Hebei and surrounding " $2+26$ " cities around the 2020 Spring Festival, with focuses on the impacts of meteorological conditions and the comprehensive emission reduction requirements of major air pollutants.

Scholars have carried out a lot of works to study the impact of meteorological conditions on air quality (Lü et al., 2019; Lin et al., 2019; Chen et al., 2017; Chuang et al., 2017; Kozáková et al., 2017; Liu et al., 2017; Wu et al., 2017; Zhang et al., 2012). Zhang et al. (2016) studied the impact of meteorological conditions on air quality in the BeijingTianjin-Hebei region over the past 30 years from the perspective of weather type classification; Liu et al. (2017) used a numerical model to quantify the impact of meteorological conditions on $\mathrm{PM}_{2.5}$ pollution in the Beijing-Tianjin-Hebei region; Xu et al. (2019) quantitatively analyzed the impacts of meteorological conditions and air pollutant emissions on
$\mathrm{PM}_{2.5}$ pollution across China and over the key regions based on the WRF-CMAQ modelling system. Huang et al. (2020b) found that under specific meteorological conditions, the interaction of long-range transport and aerosol-boundary layer feedback would aggravate the transboundary transportation of air pollution between China's two large urban agglomerations: the Beijing-Tianjin-Hebei region and the Yangtze River Delta region. However, few studies have comparatively analyzed the meteorological conditions during different typical heavy pollution episodes. Studies have also investigated the requirements of air pollutant emission reductions under different air pollution control objectives. Ren et al. (2000) quantified the maximum allowable $\mathrm{SO}_{2}$ emissions constrained by the national standard of annual average $\mathrm{SO}_{2}$ concentrations. Xue et al. (2014) simulated and calculated the maximum allowable emissions of major air pollutants in China with a constrain of the national standard for annual average $\mathrm{PM}_{2.5}$ concentrations (GB3095-2012). Wang et al. (2016) developed a three-dimensional iterative algorithm for estimating the atmospheric capacity of multiple air pollutants. Yet, few studies have analyzed the maximum allowable emissions of major air pollutants and the required emission reductions for typical short term heavy pollution episodes.

The WRF-CMAQ model has been widely used in meteorological condition simulations and air quality simulations (Hu et al., 2016). This study conducts the following analyses based on the WRF-CMAQ modelling system. (1) Impacts of unfavorable meteorological conditions and reductions in air pollutant emissions on $\mathrm{PM}_{2.5}$ concentrations: three typical heavy pollution episodes (including an episode around the 2020 Spring Festival) in the " $2+26$ " city after the year 2015 are selected; the sensitivity test method of "varying meteorological conditions with fixed emissions" is applied to reveal the impact of meteorological conditions on the heavy pollution episodes around the 2020 Spring Festival, which further supports the analysis of the impacts of emission variations on the heavy pollution episodes. (2) Analysis of requirements for emission reductions: targeting the heavy pollution episodes around the 2020 Spring Festival, different emission reduction ratios are set to estimate the emission reductions required to generally eliminate regional heavy pollution episodes. (3) Analysis of the difference in atmospheric environmental capacity between the pollution episode and the clean period around the 2020 Spring Festival: targeting a clean period after the heavy pollution episode around the 2020 Spring Festival, different emission increment ratios are set to quantify the difference in atmospheric environmental capacity between the pollution episode and the clean period. This study for the first time reveals the reasons for the heavy pollution episode around the 2020 Spring Festival from the perspective of meteorological conditions and emission reduction require- 
ments. It is of great significance to guide the management of the atmospheric environment and the response to heavy pollution episodes.

\section{Data and method}

The model simulation domain covers the whole China, with a focus on the Beijing-Tianjin-Hebei and surrounding "2 +26 " cities.

\subsection{Data source}

\subsubsection{Emission inventory of air pollutants}

Emissions of $\mathrm{SO}_{2}, \mathrm{NO}_{x}$, particulate matters $\left(\mathrm{PM}_{10}, \mathrm{PM}_{2.5}\right.$, and their compositions), $\mathrm{NH}_{3}$, and volatile organic compounds (VOCs; containing multiple chemical compositions) and other pollutants are required as the inputs to the CAMQ model. In this study, the initial air pollutant emission inventory is retrieved from the 2017 Multi-resolution Emission Inventory for China (MEIC, http://www.meicmodel.org). These anthropogenic emissions of $\mathrm{SO}_{2}, \mathrm{NO}_{x}, \mathrm{PM}_{10}, \mathrm{PM}_{2.5}$, $\mathrm{BC}, \mathrm{OC}, \mathrm{NH}_{3}$, and VOCs around the 2020 Spring Festival (January to Februray 2020) are then iteratively corrected based on the observed $\mathrm{PM}_{2.5}$ concentrations. Biogenic emissions of VOCs are calculated using the Model of Emissions of Gases and Aerosols from Nature model (MEGAN; Guenther et al., 2006). The basic assumption of the iterative correction of the emission inventory is that, under the condition that changes in emissions are small, the non-linear relationship between emissions and $\mathrm{PM}_{2.5}$ concentrations can be approximated as a series of linear relationships over small segments (Xue et al., 2014). Based on this assumption, the city-specific ratios between the simulated $\mathrm{PM}_{2.5}$ concentration and the observed $\mathrm{PM}_{2.5}$ concentration can be used as weighting coefficients to formulate a city-specific strategy for emission inventory correction (Xue et al., 2014). Multiple iterations of the corrections are conducted based on the air quality model until the differences between the simulated $\mathrm{PM}_{2.5}$ concentrations and the observed $\mathrm{PM}_{2.5}$ concentrations in the " $2+26$ " cities are less than $10 \%$ (Xue et al., 2014). We then obtain the final emission inventory of air pollutants. In this study, the observation data from October 2019 to December 2019 is set as the constraint target, and the baseline emission inventory of major air pollutants in the autumn and winter of 2019 to 2020 ("baseline" emission inventory for 2019-2020 cold season) is obtained through iterative corrections. The observation data during January to February 2020 is then set as a constraint target, and the emission inventory of major air pollutants around the 2020 Spring Festival ("epidemic" emission inventory) is further obtained through iterative corrections. The difference between the simulated $\mathrm{PM}_{2.5}$ concentration over the " $2+26$ " cities based on the final "epidemic" emission inventory and the observed $\mathrm{PM}_{2.5}$ concentrations around the 2020 Spring Festival is about $8 \%$. The emissions are corrected using the following equations.

$E_{i j}=E_{i-1, j} \times \frac{C_{m, j}}{C_{s(i-1, j)}}$,

$\left|\frac{C_{m}-C_{s}}{C_{m}}\right| \leq 10 \%$,

where $i$ represents times of iteration; $j$ represents one of the " $2+26$ " cities; $E_{i j}$ represents air pollutant emissions for city $j$ after $i$ times of iteration (unit: $\mathrm{kg} \mathrm{d}^{-1}$ ); $E_{i-1, j}$ represents air pollutant emissions for city $j$ after $i^{-1}$ times of iteration (unit: $\left.\mathrm{kg} \mathrm{d}^{-1}\right) ; C_{m, j}$ represents observed $\mathrm{PM}_{2.5}$ concentration in city $j$ (unit: $\mu \mathrm{g} \mathrm{m}^{-3}$ ); $C_{s(i-1, j)}$ represents simulated $\mathrm{PM}_{2.5}$ concentration after $i-1$ times of iteration on the emission inventory $\left(\mu \mathrm{g} \mathrm{m}^{-3}\right.$ ). In eq. (2), $C_{m}$ represents the mean observed $\mathrm{PM}_{2.5}$ concentrations over the " $2+26$ " cities (unit: $\mu \mathrm{g} \mathrm{m}^{-3}$ ); $C_{s}$ represents the mean simulated $\mathrm{PM}_{2.5}$ concentrations over the " 2 +26 " cities (unit: $\mu \mathrm{g} \mathrm{m}^{-3}$ ).

\subsubsection{Air quality monitoring data}

The air quality monitoring data are collected from the Data Center of the Ministry of Ecology and Environment of the People's Republic of China. Daily mean $\mathrm{PM}_{2.5}$ concentrations of the Beijing-Tianjin-Hebei and surrounding " $2+26$ " cities are collected.

\subsection{Model configuration}

\subsubsection{Simulation periods}

By analyzing the daily mean $\mathrm{PM}_{2.5}$ concentration from January 2015 to February 2020, this study selects three typical heavy pollution episodes and a clean period after the heavy pollution episode around the 2020 Spring Festival (Table 1)

Table 1 Different cases considered in this study

\begin{tabular}{|c|c|c|c|}
\hline Case name & Simulation period & Analysis period & $\begin{array}{l}\text { Observed mean } \mathrm{PM}_{2.5} \text { levels in heavily } \\
\text { or more polluted days }\left(\mu \mathrm{g} \mathrm{m}^{-3}\right)\end{array}$ \\
\hline Episode around the 2020 Spring Festival (case 1) & $2020-01-19-2020-02-15$ & $2020-01-22-2020-02-14$ & 195 \\
\hline Episode around 2017 New Year's Day (case 2) & 2016-12-13-2017-01-14 & 2016-12-16-2017-01-14 & 240 \\
\hline Episode around 2015 Christmas Day (case 3) & $2015-12-15-2015-12-26$ & $2015-12-18-2015-12-26$ & 284 \\
\hline Clean period during the 2020 Spring Festival (case 4 ) & $2020-02-12-2020-02-17$ & $2020-02-15-2020-02-17$ & - \\
\hline
\end{tabular}


to analyze the causes of the heavy pollution episode around the 2020 Spring Festival. Three days of spin-up is applied to the simulations of all cases.

\subsubsection{Model domain}

The CMAQ model in this study is based on a Lambert projection with an origin of $103^{\circ} \mathrm{E}, 37^{\circ} \mathrm{N}$, and two parallel latitudes of $25^{\circ} \mathrm{N}$ and $40^{\circ} \mathrm{N}$. The horizontal simulation range is $-2690-2690 \mathrm{~km}$ over the $X$ direction and $-2150-2150 \mathrm{~km}$ over the $Y$ direction. The grid spacing is set to $20 \mathrm{~km}$, and the study domain is divided into $270 \times 216$ grid cells in total. Vertically, 14 pressure layers are set with the layer spacing gradually increases from bottom to top (Xu et al., 2017).

\subsubsection{Meteorological simulations}

The meteorological field required by the CMAQ model is provided by the Weather Research and Forecasting model (WRF). The WRF model and the CMAQ model use the same simulation time period and spatial projection coordinate system. In the WRF model, a total of 35 pressure layers are set in the vertical direction, and the layer spacing gradually increases from bottom to top. The meteorological initial and boundary conditions are provided by the global reanalysis data from the National Centers for Environmental Prediction Final Analysis (NCEP-FNL) (http://rda.ucar.edu/datasets/ ds083.2/), with a temporal resolution of $6 \mathrm{~h}$ and the spatial resolution of $1^{\circ}$. The WRF model is restarted every day and each simulation is run for $30 \mathrm{~h}$, with the first $6 \mathrm{~h}$ as the spinup. The NCEP Automated Data Processing (ADP) observation data (http://rda.ucar.edu/datasets/ds461.0/) are used for objective analysis and data assimilation.

\subsubsection{Model evaluation}

The models used in this study are configured following previous studies (Xu et al., 2017; Xue et al., 2014). In the four cases of analysis, the meteorological conditions and pollutant emissions are consistent in time only in case 1 and case 4 . We therefore only compare simulated $\mathrm{PM}_{2.5}$ concentrations in case 1 and case 4 with the observed $\mathrm{PM}_{2.5}$ concentrations. Based on the "Guidelines for selection of ambient air quality models (on trial)", normalized mean bias (NMB), normalized mean error (NME), and the correlation coefficient (r) are used as parameters to test the model performance. The criteria for $\mathrm{PM}_{2.5}$ are $-50 \%<\mathrm{NMB}<80 \%$, $\mathrm{NME}<150 \%, R^{2}>0.3$. Figure 1 shows the comparison between simulated and observed $\mathrm{PM}_{2.5}$ concentrations. Table 2 documents the results for the considered statistical parameters, where $\mathrm{n}$ represents the sample number of data pairs in the " $2+26$ " cities during the analysis period. In case 1 that uses the "baseline" emission inventory for the 2019-2020 cold season, the correlation coefficient between simulated and observed $\mathrm{PM}_{2.5}$ concentrations is 0.59 , and NMB and NME of the simulated $\mathrm{PM}_{2.5}$ concentrations are $33.75 \%$, $47.90 \%$, with the simulated $\mathrm{PM}_{2.5}$ concentrations substantially higher than the observed values. In case 1 and case 4 that uses the "epidemic" emission inventory, the correlation coefficients, NMB, and NME are $0.60,7.00 \%, 35.14 \%$, respectively, for case 1 , and are $0.61,-0.34 \%$, and $24.90 \%$, respectively, for case 4 . These evaluation results show that cases use the "epidemic" emission inventory outperform the case that uses the "baseline" emission inventory for the 2019-2020 cold season, indicating that the "epidemic" emission inventory obtained in this study by the iterative correction is reliable and the model performance is acceptable.

\section{Results and discussion}

\subsection{Impacts of meteorological conditions on the heavy pollution episode around the 2020 Spring Festival}

The atmospheric self-cleaning ability index (ASI) can be used to characterize the ability of meteorological conditions to remove air pollutants. The higher the ASI value, the stronger the atmospheric self-cleaning ability (Zhu et al., 2018). The average ASI can characterize the average meteorological conditions during the simulation period. But this average ASI does not well characterize the short-term abrupt extreme adverse meteorological conditions, which are the major reason for the occurrence of heavy pollution episodes.
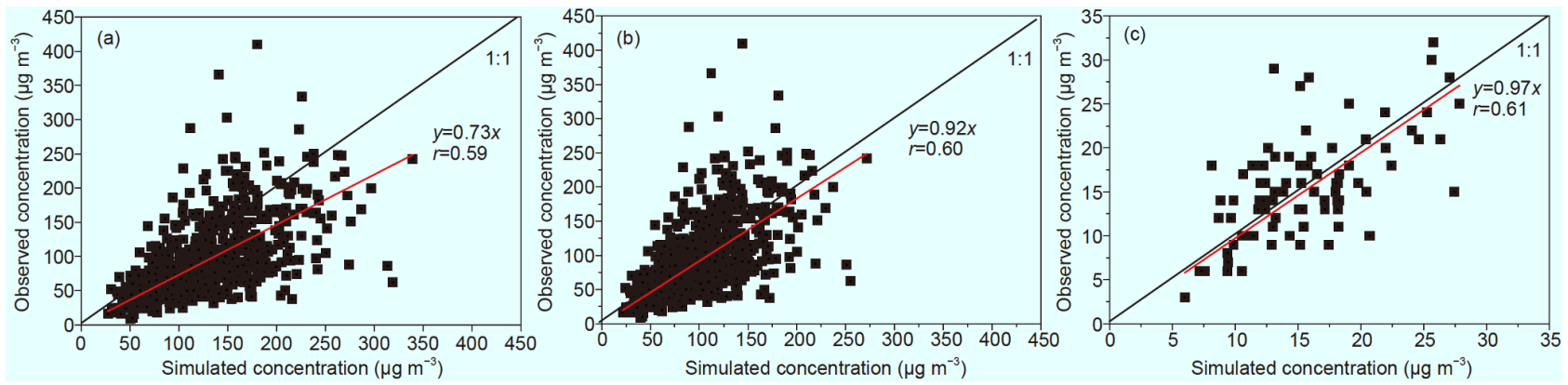

Figure 1 Correlation between simulated and observed $\mathrm{PM}_{2.5}$ concentrations. (a) Results for case 1 based on the "baseline" 2019-2020 cold season emission inventory; (b) results for case 1 based on the "epidemic" emission inventory; (c) results for case 4 based on the "epidemic" emission inventory. 
Table 2 Statistics on the evaluation of simulated $\mathrm{PM}_{2.5}$ concentrations ${ }^{\mathrm{a}}$ )

\begin{tabular}{ccccc}
\hline & $n$ & $r$ & NMB & NME \\
\hline Case 1 & 672 & 0.59 & $33.75 \%$ & $47.90 \%$ \\
Case 1 $^{*}$ & 672 & 0.60 & $7.00 \%$ & $35.14 \%$ \\
Case 4 & 84 & 0.61 & $-0.34 \%$ & $24.90 \%$ \\
\hline
\end{tabular}

a) Case 1, simulation is based on the "baseline" 2019-2020 cold season emission inventory; case 1 , , simulation is based on the "epidemic" emission inventory; case 4 , simulation is based on the "epidemic" emission inventory

The minimum value of daily ASI, however, characterizes the short-term extreme adverse meteorological conditions during the simulation period. For this reason, based on WRFsimulated meteorological parameters, including boundary layer height, wind speed, and precipitation, this study calculates the average value and minimum daily value of ASI during the simulation period for case 1 , case 2 , and case 3 (Figures 2 and 3). Based on the period average value of ASI, compared with case 2 and case 3, the averaged meteorological conditions are not the worst in case 1 (Figure 2). However, based on the minimum daily value of ASI, the selfcleaning ability of case 1 and case 2 are similar in magnitude, much worse than that of case 3 .

ASI can be used to estimate the atmospheric self-cleaning ability based on a few meteorological parameters. However, what ASI characterizes is the "static self-cleaning ability", which cannot characterize the dynamic transport effect of air pollutants in an area driven by the meteorological conditions. Therefore, in addition to the ASI analysis, we further use the WRF-CMAQ model to compare the meteorological conditions in case 1 , case 2 , and case 3 , by using the sensitivity test method of "varying meteorological conditions with fixed emissions" (Figure 4). On the regional average basis, with the same air pollutant emissions, the daily maximum $\mathrm{PM}_{2.5}$ concentration in case 1 is estimated to be $271 \mu \mathrm{g} \mathrm{m}^{-3}$, higher than the maximum values in case 2 and case 3 (Table 3 ). In case 1 , the average $\mathrm{PM}_{2.5}$ concentration for days that are
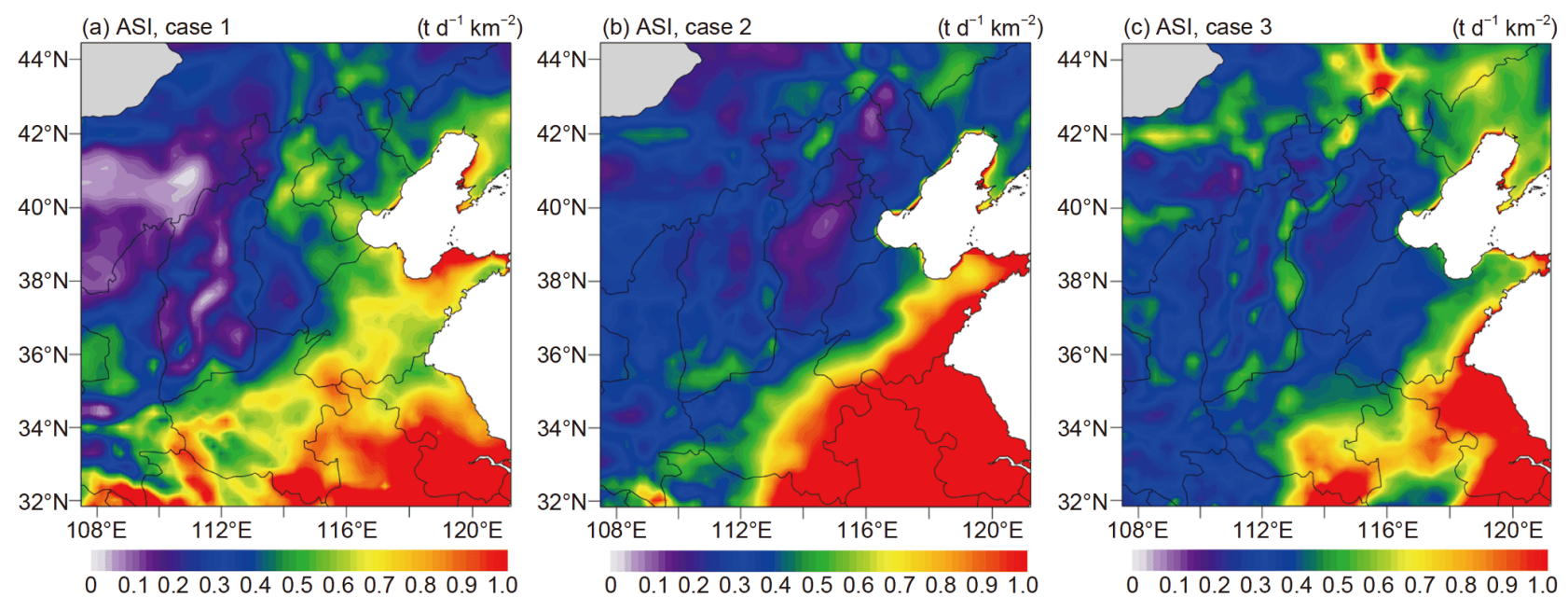

Figure 2 The average value of atmospheric self-cleaning ability index (ASI). (a) Case 1; (b) case 2; (c) case 3.

(a) ASI, case 1

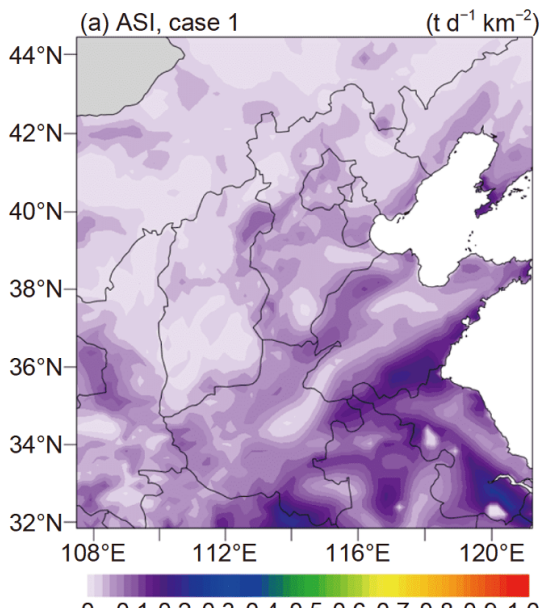

(b) ASI, case 2

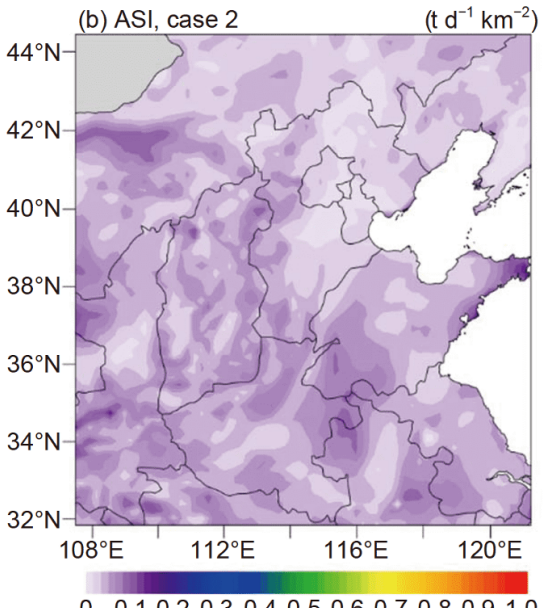

(c) ASI, case 3

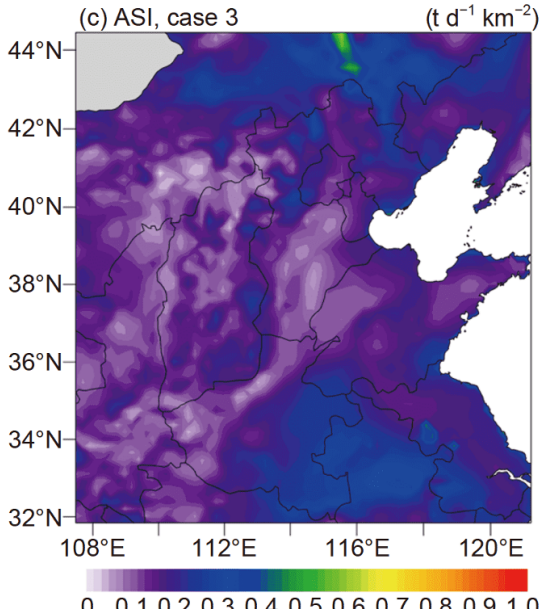

Figure 3 Minimum daily value of atmospheric self-cleaning ability index (ASI). (a) Case 1; (b) case 2; (c) case 3. 


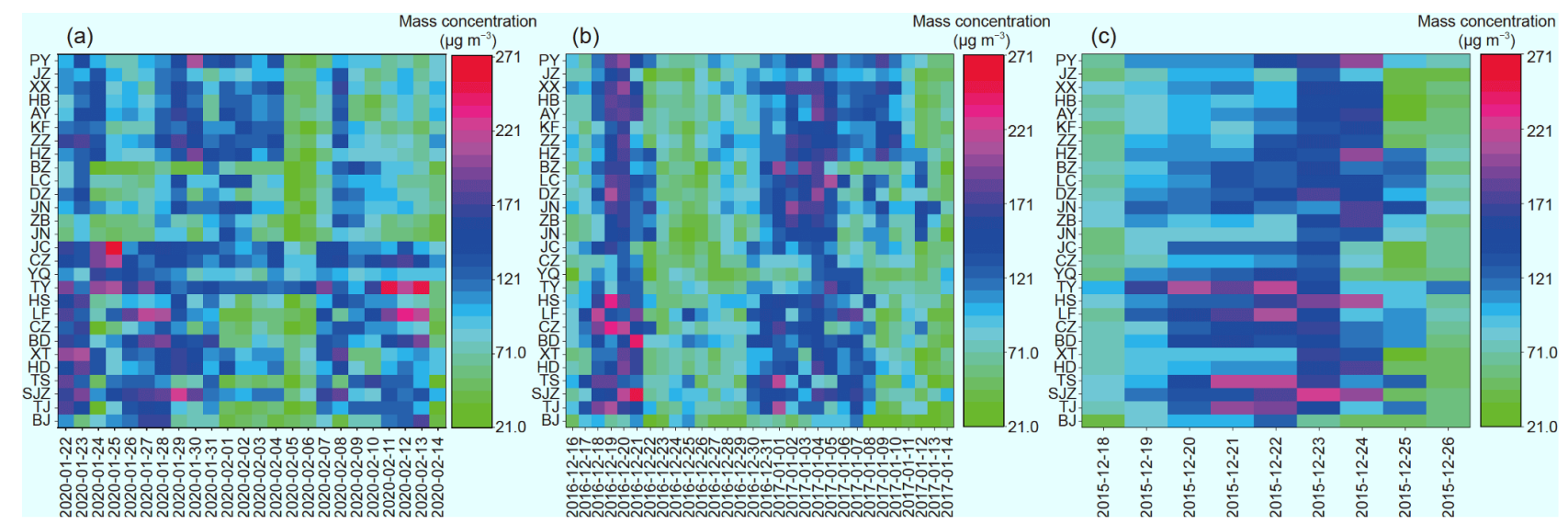

Figure 4 Simulated $\mathrm{PM}_{2.5}$ concentrations based on fixed air pollutant emission inventory $\left(\mu \mathrm{g} \mathrm{m}^{-3}\right)$. (a) Meteorological conditions in case 1: episode occurred around the 2020 Spring Festival; (b) Meteorological conditions in case 2: episode occurred around New Year's Day in 2017; (c) Meteorological conditions in case 3: episode occurred around Christmas Day in 2015. Emissions intensity of air pollutants are fixed at case 1 levels in all the simulations. BJ, Beijing; TJ, Tianjin; SJZ, Shijiazhuang; TS, Tangshan; HD, Handan; XT, Xingtai; BD, Baoding; CZ, Cangzhou; LF, Langfang; HS, Hengshui; TY, Taiyuan; YQ, Yangquan; CZ, Changzhi; JC, Jincheng; JN, Jinan; ZB, Zibo; JN, Jining; DZ, Dezhou; LC, Liaocheng; BZ, Binzhou; HZ, Heze; ZZ, Zhengzhou; KF, Kaifeng; AY, Anyang; HB, Hebi; XX, Xinxiang; JZ: Jiaozuo; PY, Puyang.

Table 3 Statistics on the simulated $\mathrm{PM}_{2.5}$ concentrations based on fixed air pollutant emission inventory ${ }^{\mathrm{a})}$

\begin{tabular}{cccc}
\hline Regional results & Case 1 $\left(\mu \mathrm{g} \mathrm{m}^{-3}\right)$ & Case $2\left(\mu \mathrm{g} \mathrm{m}^{-3}\right)$ & Case $3\left(\mu \mathrm{g} \mathrm{m}{ }^{-3}\right)$ \\
\hline Maximum daily mean value & 271 & 247 & 224 \\
Mean value for moderately or more polluted days & 147 & 151 & 151 \\
Mean value for heavily or more polluted days & 180 & 174 & 177 \\
\hline
\end{tabular}

a) Because we use fixed emission inventory for these simulations, the simulated $\mathrm{PM}_{2.5}$ concentrations are not comparable with the observed values. The relative magnitude of the simulated $\mathrm{PM}_{2.5}$ concentrations in different scenarios characterizes the impacts of meteorological conditions. Emissions intensity of air pollutants are fixed at case 1 levels in all the simulations.

moderately or more polluted is estimated as $147 \mu \mathrm{g} \mathrm{m}^{-3}$; results for days that are heavily or more polluted is estimated as $180 \mu \mathrm{g} \mathrm{m}^{-3}$, higher than that in case 2 and case 3 . The maximum daily $\mathrm{PM}_{2.5}$ concentrations in Beijing are estimated as 172,116 , and $125 \mu \mathrm{g} \mathrm{m}^{-3}$, respectively, for case 1 , case 2 , and case 3 . The sensitivity test based on the "varying meteorological conditions with fixed emissions" approach indicates that the meteorological conditions of the heavy pollution episode occurred around the 2020 Spring Festival are the worst among the three typical heavy pollution episodes after 2015.

\subsection{Threshold for regional emissions to eliminate heavy pollution episodes under unfavorable meteorological conditions}

In this section, we focus on case 1 , the case with the worst meteorological conditions that occurred around the 2020 Spring Festival. We analyze to what extent should the emissions be reduced to generally eliminate the regionwide and continuous heavy pollution episodes. In this research, we define that avoiding the simultaneous occurrence of severe pollution episodes in three or more cities is regarded as a sign of generally eliminating regionwide severe pollution.
Avoiding the simultaneous occurrence of heavy or severe pollution episodes in five or more cities and avoiding heavy or severe pollution episodes that last three or more consecutive days in any cities are regarded as the sign of generally eliminating regionwide and continuous heavy pollution episodes (Table 4). The heavy pollution episodes are mainly caused by physical transport and chemical reactions of regional air pollutant emissions. Therefore, regionwide joint emission controls are necessary to tackle the heavy pollution episodes. We thus set a baseline scenario and seven regional emission reduction scenarios for cases 1 to test emission reductions required to eliminate the heavy pollution episode occurred around the 2020 Spring Festival. The seven emission reduction scenarios are configured with regional air pollutant emission, reduced by $20 \%, 30 \%, 40 \%, 50 \%, 60 \%$, $70 \%$, and $80 \%$, respectively. The relative ratios of $\mathrm{PM}_{2.5}$ reductions in the seven emission reduction scenarios compared with the baseline scenario are acquired based on the WRF-CMAQ model. To reduce the systematic uncertainty introduced by the WRF-CMAQ model, the quantified relative reduction ratio is then applied to the observed $\mathrm{PM}_{2.5}$ concentration, and the corrected (observation-based) $\mathrm{PM}_{2.5}$ concentrations in each of the seven emission reduction scenarios are then derived. Figure 5 shows the simulated $\mathrm{PM}_{2.5}$ 
Table 4 Statistics on the pollution levels in scenarios with different emission reduction ratios during the heavy pollution episode around the 2020 Spring Festival

\begin{tabular}{|c|c|c|c|c|c|c|}
\hline $\begin{array}{l}\text { Emission } \\
\text { reduction ratio }\end{array}$ & $\begin{array}{l}\text { Times severe pollution } \\
\text { occurred simultaneous } \\
\text { in three or more cities }\end{array}$ & $\begin{array}{l}\text { Times heavy or severe } \\
\text { pollution occurred } \\
\text { simultaneous in five } \\
\text { or more cities }\end{array}$ & $\begin{array}{l}\text { Times heavy or severe } \\
\text { pollution last three or } \\
\text { more consecutive days } \\
\text { in one city }\end{array}$ & $\begin{array}{l}\text { Number of heav- } \\
\text { ily or more pol- } \\
\text { luted days }\end{array}$ & $\begin{array}{l}\text { Number of mod- } \\
\text { erately or more } \\
\text { polluted days }\end{array}$ & $\begin{array}{l}\text { Number of } \\
\text { slightly or more } \\
\text { polluted days }\end{array}$ \\
\hline 0 & 1 & 8 & 15 & 113 & 187 & 375 \\
\hline $20 \%$ & 1 & 5 & 6 & 59 & 139 & 289 \\
\hline $30 \%$ & 0 & 2 & 1 & 37 & 104 & 239 \\
\hline $40 \%$ & 0 & 1 & 1 & 19 & 64 & 187 \\
\hline $50 \%$ & 0 & 0 & 0 & 6 & 33 & 147 \\
\hline $60 \%$ & 0 & 0 & 0 & 3 & 11 & 90 \\
\hline $70 \%$ & 0 & 0 & 0 & 1 & 4 & 41 \\
\hline $80 \%$ & 0 & 0 & 0 & 0 & 1 & 6 \\
\hline
\end{tabular}

concentrations on February 8, 2020, in different emission reduction scenarios: the larger the emission reduction ratio, the lower the $\mathrm{PM}_{2.5}$ concentrations. The simulation results (Table 4) indicate that, a $20 \%$ reduction in air pollutant emissions during January to February 2020 could generally eliminate regionwide severe pollution episodes. A $40 \%$ reduction in air pollutant emissions during January to February 2020 could generally eliminate regionwide and continuous heavy pollution episodes. Yet local heavy pollution episodes may still occur over some cities. Therefore, while strengthening regional joint prevention and control, we should still pay attention to local emission reductions in specific cities.

During January to February 2020, no severe pollution episodes occurred in Beijing. During this period, six heavily polluted days occurred in Beijing, and the number of heavy pollution episodes lasts three or more consecutive days is two. The simulation results indicate that, more than $20 \%$ reductions in emissions over the " $2+26$ " cities can help Beijing to avoid heavy pollution episodes that last three or more consecutive days during January to February 2020.

\subsection{The maximum allowable regional air pollutant emissions under favorable meteorological conditions}

The atmospheric environmental capacity or the maximum allowable air pollutant emissions under a specific air quality target changes substantially along with the changes in meteorological conditions. To explore the differences in the atmospheric environmental capacity between the heavy pollution episode and the clean period around the 2020 Spring Festival, this section focuses on a clean period (February 15-17, 2020; snowy and windy days) after the heavy pollution episode. The anthropogenic emission used here is the same as that used in section 3.2, which is the "epidemic" emission inventory obtained by the iterative correction approach. For this clean period, we also set a baseline scenario and seven emission increment scenarios: emissions of air pollutants are multiplied by $2,3,4,5,10,15$,
20, respectively. The relative ratio of $\mathrm{PM}_{2.5}$ increment in the seven emission increment scenarios compared with the baseline scenario are acquired by the WRF-CMAQ model. To reduce the systematic uncertainty introduced by the WRF-CMAQ model, the quantified relative increment ratio is then applied to the observed $\mathrm{PM}_{2.5}$ concentration, and the corrected (observation-based) $\mathrm{PM}_{2.5}$ concentrations in each of the seven emission increment scenarios are then derived. Figure 6 shows the simulated $\mathrm{PM}_{2.5}$ concentrations on February 16,2020 , in different emission increment scenarios. The simulation results show that in this typical clean period, moderate pollution only occurs in a few cities when the emissions are multiplied by 5 ; regionwide heavy pollution episodes would occur only when the emissions are multiplied by 10 (Table 5).

\subsection{Discussion}

Daily emissions of $\mathrm{SO}_{2}, \mathrm{NO}_{x}$, and $\mathrm{PM}_{2.5}$ for the " $2+26$ " cities from October to December 2017 are estimated as 5183, 11127 , and 5833 tons, respectively, according to the MEIC model. These values are corrected to 3467,9406 , and 4333 tons, respectively, for the period October to December 2019 based on our iterative correction approach. The average reduction rate for these air pollutants is about $25 \%$ in two years. These corrected values are used to represent the "baseline" emission inventory for the 2019-2020 cold season. These "baseline" 2019-2020 cold season emission intensity is further corrected based on the observed $\mathrm{PM}_{2.5}$ during January to February 2020. The results show that the daily emissions of $\mathrm{SO}_{2}, \mathrm{NO}_{x}$, and $\mathrm{PM}_{2.5}$ during January to February 2020 are estimated as 2358, 6396, 2946 tons, respectively, about 32\% lower than the "baseline" 2019-2020 cold season emissions. Emission reductions are estimated to have reduced the $\mathrm{PM}_{2.5}$ concentrations averaged over January 22 th to February 14th, 2020 (case 1) by $27 \%$ as compared with the "baseline" 2019-2020 cold season emission situation. 

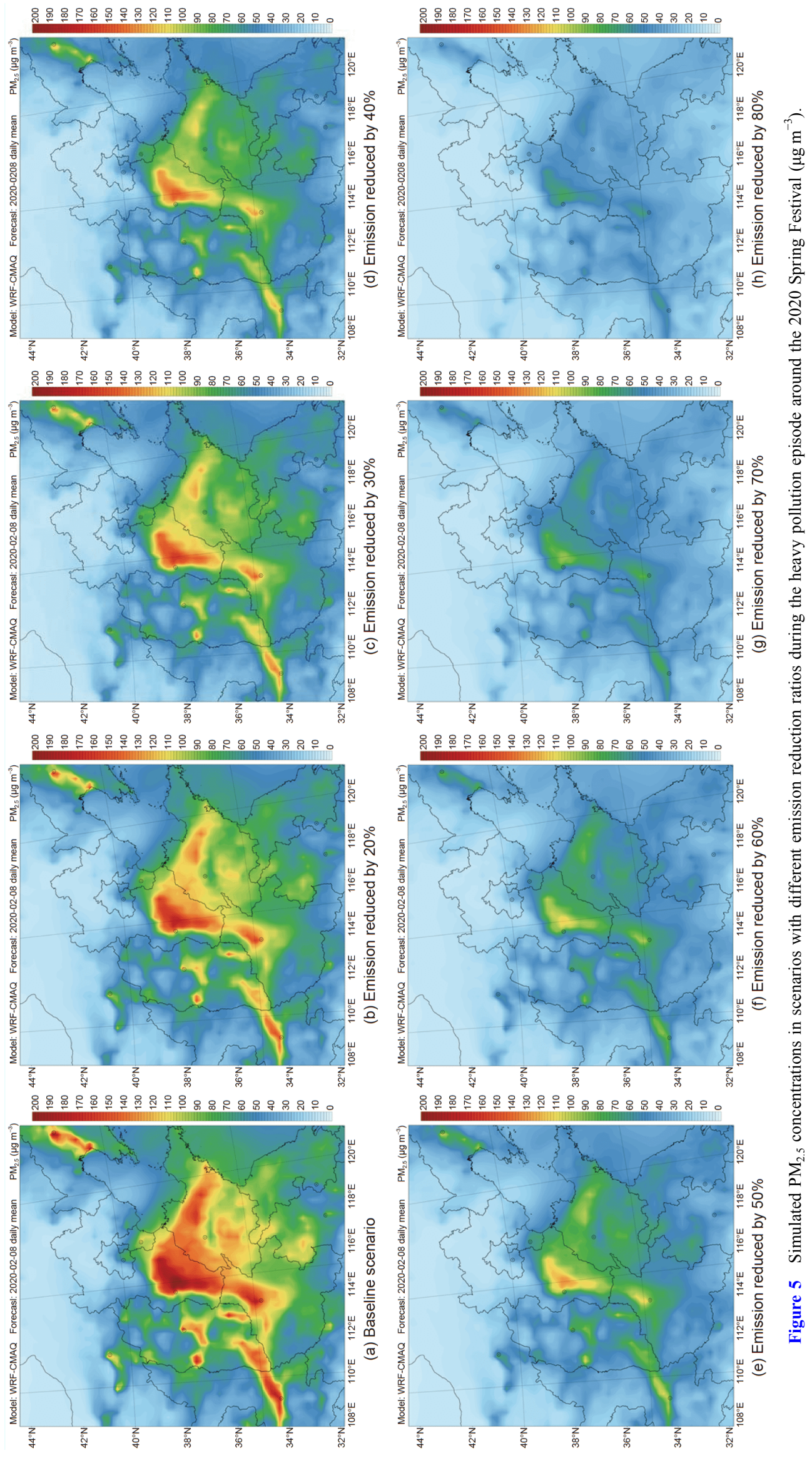

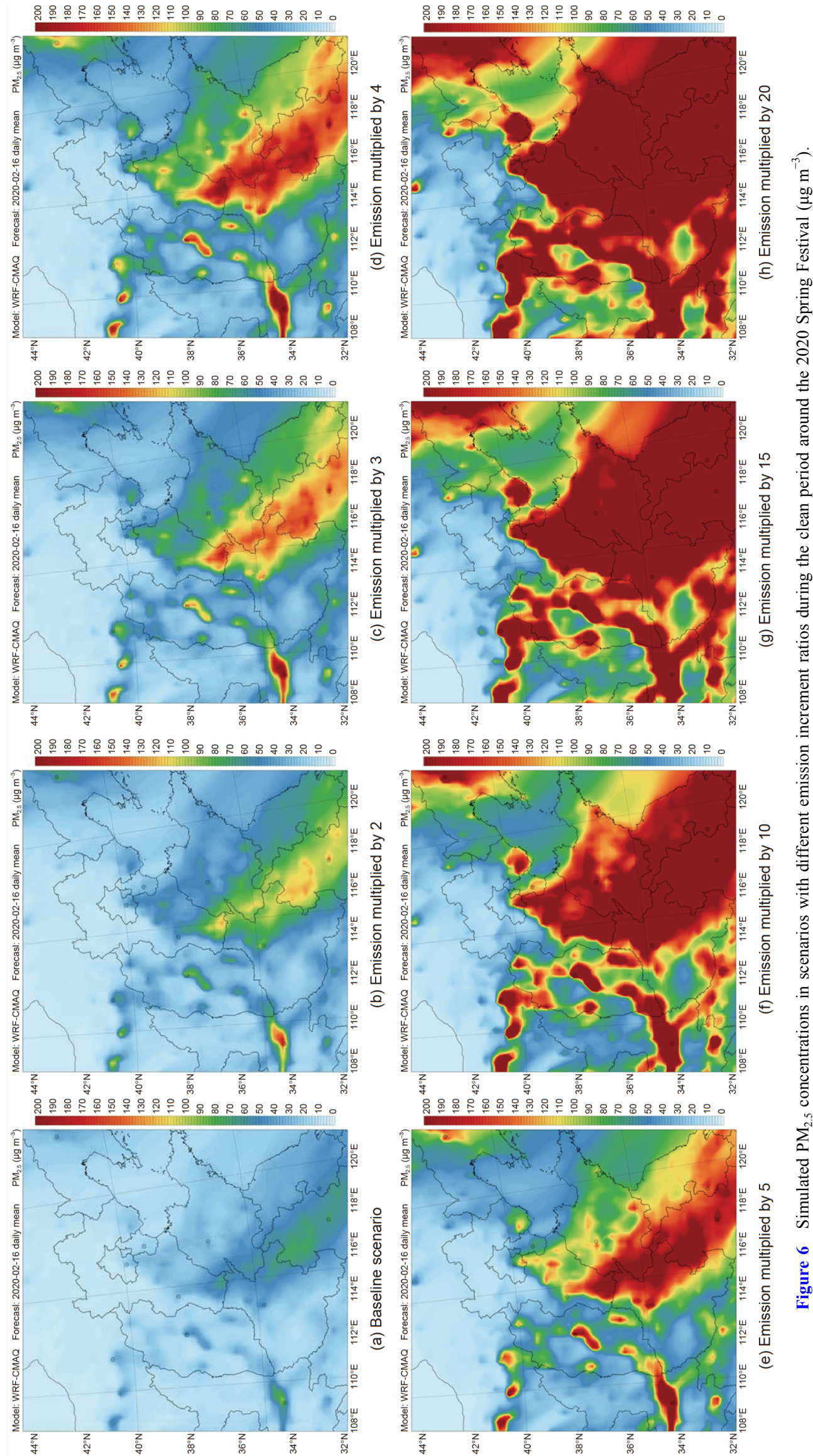
Table 5 Statistics on the pollution levels in scenarios with different emission increment ratios during the clean period around the 2020 Spring Festival

\begin{tabular}{cccccc}
\hline $\begin{array}{c}\text { Emissions } \\
\text { multiply by }\end{array}$ & $\begin{array}{c}\text { Times heavy or severe } \\
\text { pollution occurred simultaneous } \\
\text { in five or more cities }\end{array}$ & $\begin{array}{c}\text { Times heavy or severe } \\
\text { pollution last three or more } \\
\text { consecutive days in one city }\end{array}$ & $\begin{array}{c}\text { Number of heavily } \\
\text { or more polluted days }\end{array}$ & $\begin{array}{c}\text { Number of moderately } \\
\text { or more polluted days }\end{array}$ & $\begin{array}{c}\text { Number of slightly } \\
\text { or more polluted days }\end{array}$ \\
\hline 1 & 0 & 0 & 0 & 0 & 0 \\
2 & 0 & 0 & 0 & 0 & 0 \\
3 & 0 & 0 & 0 & 0 & 1 \\
4 & 0 & 0 & 0 & 2 & 7 \\
5 & 0 & 0 & 0 & 36 & 6 \\
10 & 1 & 0 & 14 & 66 & 76 \\
20 & 3 & 8 & 47 & 66 & 76 \\
\hline
\end{tabular}

Studies by the National Joint Research Center for Tackling Key Problems in Air Pollution Control also found that emissions of $\mathrm{SO}_{2}, \mathrm{NO}_{x}, \mathrm{PM}_{2.5}$, and VOCs in the " $2+26$ " cities have reduced by $20-30 \%$ during the 2020 Spring Festival (http://www.mee.gov.cn/xxgk2018/xxgk/xxgk15/202002/ t20200211_762584.html). Among major emission sectors, emissions from vehicle and fugitive dust have decreased notably; emissions from thermal power plants and the iron and steel industry have decreased by about $10 \%$; but emissions from coking, petrochemical, glass, and nonferrous industries, and other industries show no notable trend. In some of the rural areas, coal has been substituted by natural gas and electricity. However, there are still more than 10 million households are burning coal for heating in the winter. Observational data also shows that $\mathrm{CO}$ concentration, which is an indicator of the amount of coal burned, has increased in rural areas, indicating that the emissions from civil bulk coal consumption have not decreased.

Meteorological conditions in case 1, the heavy pollution episode around the 2020 Spring Festival, are the most unfavorable compared with case 2 (the pollution episode occurred around New Year's Day in 2017) and case 3 (the pollution episode occurred around Christmas Day in 2015). The atmospheric environmental capacity is also the lowest in case 1. If air pollutant emissions are the same in the three cases, air pollution levels in case 1 would be the highest. However, due to the substantial reductions in air pollutant emissions in the " $2+26$ " cities in recent years, the actual air pollution level in case 1 is much lower than in case 2 and case 3 . In case 1 , the observed maximum daily mean $\mathrm{PM}_{2.5}$ concentrations, mean $\mathrm{PM}_{2.5}$ concentrations in moderately or more polluted days, and mean $\mathrm{PM}_{2.5}$ concentrations in heavily or more polluted days are $47.2 \%, 19.8 \%$, and $18.7 \%$ lower than the air pollution episode occurred around New Year's Day in 2017 (case 2), respectively. Therefore, reducing air pollutant emissions is the main driving factor in improving air quality and reducing the occurrence frequency of heavy pollution episodes.

In addition, analysis of the clean period around the 2020
Spring Festival (case 4) has shown that at least a 10-fold increase in air pollutant emissions could result in a regionwide heavy pollution episode. On the other hand, analysis of the heavy pollution episode around the 2020 Spring Festival (case 1) shows that to eliminate the regionwide and continuous heavy pollution episodes, air pollutant emissions have to be reduced by $40 \%$ compared with the "epidemic" emission levels, or by $60 \%$ compared with the "baseline" 2019-2020 cold season emission levels. The "epidemic" emission levels are only $32 \%$ lower than the "baseline" 2019-2020 cold season emission, smaller than the required $60 \%$ reductions in emissions. This unmet requirement in emission reductions is the fundamental reason for the occurrence of the heavy pollution episode around the 2020 Spring Festival.

\section{Conclusion}

(1) Meteorological conditions for the " $2+26$ " cities are the worst during the heavy pollution episode around the 2020 Spring Festival as compared with two other typical heavy pollution episodes that occurred after 2015 .

(2) During January to February 2020, compared with the actual emission levels, a $20 \%$ reduction in air pollutant emissions could help to generally eliminate regionwide severe pollution episodes, and avoid heavy pollution episodes that last three or more consecutive days in Beijing; a $40 \%$ reduction in emissions could help to generally eliminate regionwide and continuous heavy pollution episodes.

(3) During the clean period after the heavy pollution episode around the 2020 Spring Festival, the regionwide heavy pollution episode would only occur with at least a 10 -fold increase in air pollutant emissions.

(4) The unfavorable meteorological condition is an important external cause of the heavy pollution episode in the " $2+26$ " cities around the 2020 Spring Festival. And the far exceeding of air pollutant emissions than the atmospheric environmental capacity is the main internal cause of the 
heavy pollution episode. Emissions of major air pollutants during the epidemic have been reduced substantially and have effectively suppressed the spatial extent and intensity of the heavy pollution episode. However, air pollutant emissions during the epidemic are only $32 \%$ lower than the "baseline" emission levels during the 2019-2020 cold season, while at least $60 \%$ reductions in emissions are required to generally eliminate regionwide and continuous heavy pollution episodes.

Acknowledgements This work was supported by the National Key Research and Development Program (Grant Nos. 2016YFC0207502, 2016YFC0208805), the National Research Program for Key Issues in Air Pollution Control (Grant No. DQGG0302).

\section{References}

Chang X, Wang S X, Zhao B, Xing J, Liu X X, Lin W, Song Y, Wu W J, Cai S Y, Zheng H T, Ding D, Zheng M. 2019. Contributions of intercity and regional transport to $\mathrm{PM}_{2.5}$ concentrations in the BeijingTianjin-Hebei region and its implications on regional joint air pollution control. Sci Total Environ, 660: 1191-1200

Chen Z, Cai J, Gao B, Xu B, Dai S, He B, Xie X. 2017. Detecting the causality influence of individual meteorological factors on local $\mathrm{PM}_{2.5}$ concentration in the Jing-Jin-Ji region. Sci Rep, 7: 40735

Cheng Y H, Li Y S. 2010. Influences of traffic emissions and meteorological conditions on ambient $\mathrm{PM}_{10}$ and $\mathrm{PM}_{2.5}$ levels at a highway toll station. Aerosol Air Qual Res, 10: 456-462

Chuang M T, Chou C C K, Lin N H, Takami A, Hsiao T C, Lin T H, Fu J S, Pani S K, Lu Y R, Yang T Y. 2017. A simulation study on $\mathrm{PM}_{2.5}$ sources and meteorological characteristics at the northern tip of Taiwan in the early stage of the Asian haze period. Aerosol Air Qual Res, 17: 3166-3178

Guenther A, Karl T, Harley P, Wiedinmyer C, Palmer P I, Geron C. 2006. Estimates of global terrestrial isoprene emissions using MEGAN (Model of Emissions of Gases and Aerosols from Nature). Atmos Chem Phys, 6: 3181-3210

Hu J, Chen J, Ying Q, Zhang H. 2016. One-year simulation of ozone and particulate matter in China using WRF/CMAQ modeling system. Atmos Chem Phys, 16: 10333-10350

Huang X, Ding A, Gao J, Zheng B, Zhou D, Qi X, Tang R, Wang J, Ren C, Nie W, Chi X, Xu Z, Chen L, Li Y, Che F, Pang N, Wang H, Tong D, Qin W, Cheng W, Liu W, Fu Q, Liu B, Chai F, Davis S J, Zhang Q, He K. 2020a. Enhanced secondary pollution offset reduction of primary emissions during COVID-19 lockdown in China. Natl Sci Rev, nwaa137, doi: 10.31223/osf.io/hvuzy

Huang X, Ding A, Wang Z, Ding K, Gao J, Chai F, Fu C. 2020b. Amplified transboundary transport of haze by aerosol-boundary layer interaction in China. Nat Geosci, 13: 428-434

Kozáková J, Pokorná P, Černíková A, Hovorka J, Braniš M, Moravec P, Schwarz J. 2017. The association between intermodal $\left(\mathrm{PM}_{1-2.5}\right)$ and $\mathrm{PM}_{1}, \mathrm{PM}_{2.5}$, coarse fraction and meteorological parameters in various environments in Central Europe. Aerosol Air Qual Res, 17: 1234-1243

Lin T K, Hong L N, Huang Z C, Wang X S, Cai X H. 2019. Meteorological and pollution characteristics under atmospheric circulation types in autumn and winter in Beijing (in Chinese). China Environ Sci, 39: $1813-1822$

Liu T T, Gong S L, He J J, Yu M, Wang Q F, Li H R, Liu W, Zhang J, Li L, Wang X G, Li S L, Lu Y L, Du H T, Wang Y Q, Zhou C H, Liu H L, Zhao Q C. 2017. Attributions of meteorological and emission factors to the 2015 winter severe haze pollution episodes in China's Jing-Jin-Ji area. Atmos Chem Phys, 17: 2971-2980
Liu X, Li C, Tu H, Wu Y, Ying C, Huang Q, Wu S, Xie Q, Yuan Z, Lu Y. 2016. Analysis of the effect of meteorological factors on $\mathrm{PM}_{2.5}$-associated PAHs during autumn-winter in urban Nanchang. Aerosol Air Qual Res, 16: 3222-3229

Lü M Y, Zhang H D, Wang J K, Jiang Q, Liu C, Zhang B H, Li Q C. 2019. Analysis of meteorological causes of two heavily polluted weather processes in Beijing-Tianjin- Hebei Region in winter of 2015 (in Chinese). China Environ Sci, 39: 2748-2757

Multi-resolution emission inventory for China. http://www. meicmodel.org/

National Center for Atmospheric Research. CISL Research Data Archive. http://rda.ucar.edu/datasets/ds083.2

National Center for Atmospheric Research. CISL Research Data Archive. http://rda.ucar.edu/datasets/ds461.0

Ren Z H, Yu X Z, Yang X X, Gao Q X, Su F Q, Li L J. 2000. Method for China's air pollutants total amount control (in Chinese). Kunming: 8th China Atmospheric Environment Academic Conference

Wang H, Xu J, Zhang M, Yang Y, Shen X, Wang Y, Chen D, Guo J. 2014. A study of the meteorological causes of a prolonged and severe haze episode in January 2013 over central-eastern China. Atmos Environ, 98: $146-157$

Wang J N, Xue W B, Xu Y L, Lei Y, Ding Z Y, 2016, A three-dimensional iterative algorithm for estimating the atmospheric capacity of multiple air pollutants (in Chinese). China Patent, No. CN106649960B, 2016-10-12

Wang P, Cao J J, Tie X X, Wang G H, Li G H, Hu T F, Wu Y T, Xu Y S, Xu G D, Zhao Y Z, Ding W C, Liu H K, Huang R J, Zhan C L. 2015. Impact of meteorological parameters and gaseous pollutants on $\mathrm{PM}_{2.5}$ and $\mathrm{PM}_{10}$ mass concentrations during 2010 in Xi' an, China. Aerosol Air Qual Res, 15: 1844-1854

Wang W Y, Chen N, Ma X J. 2012. Research on atmospheric environmental capacity model of urban agglomeration. Adv Mater Res, 518523: $1311-1320$

Wu P, Ding Y, Liu Y. 2017. Atmospheric circulation and dynamic mechanism for persistent haze events in the Beijing-Tianjin-Hebei region. Adv Atmos Sci, 34: 429-440

Xu Y L, Xue W B, Lei Y. 2019. Impact of meteorological conditions and emission changes on $\mathrm{PM}_{2.5}$ pollution in China (in Chinese). China Environ Sci, 39: 4546-4551

Xu Y L, Xue W B, Lei Y, Yi A H, Wang J N, Cheng S Y, Ren Z H. 2017. Sensitivity analysis of $\mathrm{PM}_{2.5}$ pollution to ammonia emission control in China (in Chinese). China Environ Sci, 37: 2482-2491

Xu Y L, Xue W B, Wang J N, Lei Y, Ye Z L, Ren Z H. 2018. Development and prospect of atmospheric environment capacity theory and accounting method (in Chinese). Res Environ Sci, 31: 1835-1840

Xue W B, Fu F, Wang J N, He K B, Lei Y, Yang J T, Wang S X, Han B P. 2014. Modeling study on atmospheric environmental capacity of major pollutants constrained by $\mathrm{PM}_{2.5}$ compliance of Chinese cities (in Chinese). China Environ Sci, 34: 2490-2496

Xue W B, Han B P, Wang J N, Wu W L. 2017. Modeling Simulation of $\mathrm{PM}_{2.5}$ Transport Characteristics and its Environmental Capacity (in Chinese). Beijing: China Environmental Science Press. 150-160

Zhang J P, Zhu T, Zhang Q H, Li C C, Shu H L, Ying Y, Dai Z P, Wang X, Liu X Y, Liang A M, Shen H X, Yi B Q. 2012. The impact of circulation patterns on regional transport pathways and air quality over Beijing and its surroundings. Atmos Chem Phys, 12: 5031-5053

Zhang Q, Quan J, Tie X, Li X, Liu Q, Gao Y, Zhao D. 2015. Effects of meteorology and secondary particle formation on visibility during heavy haze events in Beijing, China. Sci Total Environ, 502: 578-584

Zhang Y, Ding A J, Mao H T, Nie W, Zhou D R, Liu L X, Huang X, Fu C B. 2016. Impact of synoptic weather patterns and inter-decadal climate variability on air quality in the North China Plain during 1980-2013. Atmos Environ, 124: 119-128

Zhu R, Zhang C J, Mei M. 2018. The climate characteristics of atmospheric self-cleaning ability index and its application in China (in Chinese). China Environ Sci, 38: 3601-3610 